\title{
Anomalous left coronary artery arising from the pulmonary artery in infancy: Is early operation better?
}

\author{
MAURICE KAKOU GUIKAHUE, DANIEL SIDI, JEAN KACHANER, \\ ELIZABETH VILLAIN, LAURENCE COHEN, JEAN FRANÇOIS PIECHAUD, \\ JEROME LE BIDOIS, ELISA PEDRONI, PASCAL VOUHE, JEAN YVES NEVEUX \\ From the Services de Cardiologie Pédiatrique, Départment de Pédiatrie, Hôpital des Enfants-Malades et de \\ Chirurgie Cardiovasculaire et Thoracique, Hôpital Laennec, Paris, France
}

SUMMARY From January 1975 to January 1987, 21 consecutive infants aged less than six months (mean (SD) $2.6(1 \cdot 2)$ ) were admitted with anomalous origin of the left coronary artery from the pulmonary artery. In the first 12 patients, who were seen up to 1982 , operation was performed after the age of one year (mean (SD) 29 (29) months) (group 1). The next nine infants, seen from 1983 to $\stackrel{\mathbb{D}}{ }$ 1987 , had their operations within a few weeks of the onset of symptoms (mean (SD) age $4 \cdot 8(1 \cdot 4) \vec{\bullet}$ months) (group 2). In group 2 the left coronary artery was relocated into the aorta, whereas in $\&$ group 1 there was additional resection of the left ventricular wall or mitral valvoplasty or both. At presentation there were no differences in age, clinical condition, heart enlargement, and echocardiographic left ventricular dysfunction between groups 1 and 2 . Seven of the 12 patients in group 1 died, five while they were awaiting operation (three died suddenly at home) and two at operation. The five survivors are doing well $6.4(3.1)$ years after operation with normal left $\stackrel{\mathbb{D}}{\square}$ ventricular function which improved slowly over several months after operation. Two of the nine $\overrightarrow{\vec{A}}$ patients in group 2 died; both deaths occurred at or soon after operation. The seven survivors are $\exists$ doing well $1.8(0.9)$ years after operation. In three, left ventricular function recovered within three weeks; and there was even partial or total regression of the $Q$ waves in the supposedly necrotic areas. In the remaining four the pattern of improvement in left ventricular function resembled that in group 1.

Operation should be undertaken early in infants with anomalous left coronary artery arising from the pulmonary artery because the procedure is relatively safe, prevents a high natural mortality, and offers a better chance of a faster recovery of left ventricular function.

Anomalous origin of the left coronary artery from the pulmonary artery is a rare severe congenital anomaly that often causes myocardial infarction within a few weeks of birth with subsequent ventricular dysfunction, mitral valve incompetence, and severe congestive heart failure.

There is disagreement about when to operate and whether prompt restoration of a systemic left coronary artery perfusion is important. There have been numerous conflicting reports about the risks of

Requests for reprints to Professor Jean Kachaner, Hôpital des Enfants-Malades, 149 Rue de Sèvres, 75743 Paris Cedex 15, France.

Accepted for publication 18 August 1988 medical treatment and early operation. With medical 윽 treatment, mortality in the first year of life ranges from $35 \%{ }^{1}$ to $80 \%{ }^{2}$ or even $90 \%{ }^{3}$ But many are afraid to risk open heart surgery in severely ill or infants ${ }^{14}$ when they know that the operation may not $\mathrm{N}$ be successful because myocardial infarction has $N$ usually already occurred. Nevertheless, others $\sigma$ favour a vigorous approach with early operation,,$^{25-7}$ arguing that restoration of a two coronary artery system will protect against sudden death, may lead to the quick recovery of good ventricular function, ${ }^{8}$ and avoid the late development of atherosclerosis.

These discrepancies may be attributable to the

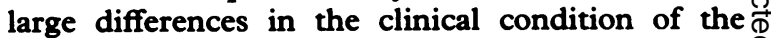
various patient populations. In some centres, only $\frac{\varrho}{\sigma}$ 
very ill patients are selected for operation ${ }^{1}$ and so the outcome with medical treatment is better; in others only the healthiest patients have operations ${ }^{4}$ and the outcome is better than with medical treatment.

We used to treat very ill infants with large myocardial infarction caused by anomalous left coronary artery arising from the pulmonary artery by a medical protocol with delayed operation (after one year of age) but since 1982 we have been operating earlier. We have examined the results of these two treatments.

\section{Patients and methods}

From January 1975 to January 1987, 21 consecutive infants (three weeks to six months old, mean (SD) $2 \cdot 6$ (1.2) months) were admitted to our department during or soon after a myocardial infarction caused by an anomalous left coronary artery arising from the pulmonary artery.

In all patients the diagnosis was suspected because the standard electrocardiogram showed a constant deep $Q$ wave in leads $I$ and aVL and sometimes in other leads too. Since 1982 cross sectional echocardiography and Doppler echocardiography have been used to identify a dilated right coronary artery, and in some the image showed continuous flow in an anomalous left coronary artery arising from the pulmonary artery. In all the patients the diagnosis was confirmed by angiography. In five the left coronary artery was seen by a direct stop-flow injection of contrast medium into the pulmonary artery'; in three the left ventricle could be entered through a patent foramen ovale and the abnormal vessel was imaged on a left ventriculogram; in the last 13 patients retrograde aortography was needed to assess the anomaly. The patients were separated into two groups according to how they were treated.

The first 12 infants were treated medically and operation was delayed until they were at least one year old (group 1). All patients but one were admitted before 1983. This infant, admitted in 1985, had a minute left coronary artery with no arterial shunting and we decided that reimplantation would be inappropriate. The survivors were operated on at a mean age of 29 (29) months (range 14-108 months).

The next nine infants had operations $0.5-4$ months after the myocardial infarction. The mean (SD) age at operation was 4.8 (1.7) months (group 2). All patients but one were admitted after January 1983. This child, admitted in 1977, had intractable heart failure with massive mitral insufficiency and a left ventricular aneurysm.

Table 1 summarises the clinical data on the patients in both groups when they were first seen in our department. All had evidence of myocardial infarction at admission and were in congestive heart failure, which in 13 was severe enough to cause low systemic output. There were no significant differences in age, clinical state, heart enlargement, or electrocardiographic findings between the two groups at that time.

Table 2 summarises the surgical management. Survivors in group $1 \mathrm{had}$ an extensive operation for relocation of the left coronary artery into the aorta and also eventually resection of the left ventricle or mitral valvoplasty or both. ${ }^{4}$ All infants in group 2, except the patient operated on in 1977, had only relocation of the left coronary artery into the aorta.

The surgical technique has been described elsewhere. ${ }^{7}$ The left coronary artery was transferred together with a sizable cuff of the pulmonary artery wall from around the ostium and was directly reimplanted, without tension, into the aorta. End to end reconstruction of the pulmonary artery was then achieved by mobilisation of the pulmonary bifurcation. In all cases the operation was performed on bypass and hypothermia. After 1983 (the last six patients) operation included 2-6 hours of left ventricular assistance on bypass at the end of the operation.

All but two of the survivors were followed up at our outpatient clinic. Two were followed up elsewhere. Every three months during the first year and then

Table 1 Preoperative data in 21 infants with anomalous left coronary artery arising from the pulmonary artery (mean (SD) )

\begin{tabular}{|c|c|c|c|c|c|c|c|c|}
\hline \multirow[b]{2}{*}{ Group * } & \multirow[b]{2}{*}{ No of cases } & \multirow{2}{*}{$\begin{array}{l}\text { Mean age } \\
\text { (months) }\end{array}$} & \multicolumn{2}{|c|}{ Clinical } & \multirow{2}{*}{$\frac{\text { Chest } x \text { ray }}{(\text { mean } C T R)}$} & \multicolumn{3}{|c|}{ Echocardiography } \\
\hline & & & $L C O$ & $A V S$ & & No of cases & $L V D D(\mathrm{~mm})$ & $\operatorname{ShFr}(\%)$ \\
\hline $\begin{array}{l}1 \\
2 \\
p \text { value }\end{array}$ & $\begin{array}{r}12 \\
9\end{array}$ & $\begin{array}{l}2.7(1.4) \\
2.5(1.3) \\
>0.5\end{array}$ & $\begin{array}{l}7 \\
6 \\
>0.5\end{array}$ & $\begin{array}{l}8 \\
6 \\
>0.5\end{array}$ & $\begin{array}{l}0.69(0.03) \\
0.70(0.03) \\
>0.5\end{array}$ & $\begin{array}{l}6 \\
9\end{array}$ & $\begin{array}{l}42(4) \\
44(4) \\
>0.5\end{array}$ & $\begin{array}{c}12(3) \\
13(4) \\
>0.5\end{array}$ \\
\hline
\end{tabular}

$\star$ See text for definitions of groups 1 and 2.

AVS, artificial ventilation support; CTR, cardiothoracic ratio; LCO, low cardiac output; LVDD, left ventricular end diastoclic diameter (M mode); ShFr, shortening fraction of the left ventricular diameter.

p Values apply to comparisons between group 1 and group 2. 
Table 2 Surgical procedure in 16 infants with anomalous left coronary artery arising from the pulmonary artery

\begin{tabular}{|c|c|c|c|c|c|c|c|}
\hline \multirow[b]{2}{*}{ Group * } & \multirow{2}{*}{$\begin{array}{l}\text { No of } \\
\text { cases }\end{array}$} & \multicolumn{3}{|c|}{ On the coronary artery } & \multicolumn{3}{|c|}{ Associated operation } \\
\hline & & $L C A R$ & Lig & $S C A A n$ & LV res & $M V p l$ & Both \\
\hline $\begin{array}{l}1 \\
2\end{array}$ & $\begin{array}{l}7 \\
9\end{array}$ & $\begin{array}{l}5 \\
9\end{array}$ & $\begin{array}{l}0 \\
0\end{array}$ & $\begin{array}{l}2 \\
0\end{array}$ & $\begin{array}{l}5 \\
1\end{array}$ & $\begin{array}{l}1 \\
0\end{array}$ & $\begin{array}{l}1 \\
0\end{array}$ \\
\hline
\end{tabular}

«See text for definition of groups 1 and 2.

LCAR, relocation of the left coronary artery into the aorta; Lig, ligation of the left coronary artery; LV res, left ventricular resection; MV $\vec{O}$ pl, mitral valvoplasty; SCAAn, anastomosis of subclavian artery to left coronary artery.

once a year each operated child was examined and had a chest $x$ ray, standard 12 lead electrocardiogram, $M$ mode and cross sectional echocardiography (since 1980), and pulsed Doppler study (since 1986). In addition, two of the survivors had retrograde aortography to assess the patency of the left coronary artery.

The results was evaluated by the analysis of variance between the two groups for the condition at admission to hospital and by $\chi^{2}$ for mortality in the two groups.

\section{Results}

GROUP I

Five $(42 \%)$ of the twelve infants died between four and nine months of age. Two had not recovered from the first episode despite intensive medical treatment including artificial ventilation; they had massive myocardial infarction with mitral insufficiency. The other three died at home after discharge from our unit on medical treatment (digoxin and frusemide) for controlled heart failure. They had persistent cardiomegaly and a dilated hypokinetic left ventricle. They were awaiting operation at the age of about two, which was thought to be the optimal age for operation. One died from infective pneumonia and the other two died suddenly from a presumed ventricular arrhythmia.

The remaining seven patients survived beyond the first year of life. They were discharged from the hospital after 3-7 weeks with controlled (six) or moderate (one) congestive heart failure with massive cardiomegaly (mean (SD) cardiothoracic ratio 0.66 $(0.03))$ and an hypokinetic left ventricle. They all had an operation between the age of 14 to 102 months (mean (SD) 29 (29) months), and at that time cardiomegaly was still present (fig 1). Two died at or soon after operation, which was extensive with left ventricular resection and, in one, mitral valvoplasty. Five survived the operation and have been followed for 4-11 years $(6 \cdot 4(3 \cdot 1)$ years). All are doing well with no symptoms and mild cardiomegaly which decreased progressively over one year (fig 1); three have recovered normal left ventricular function; $M$

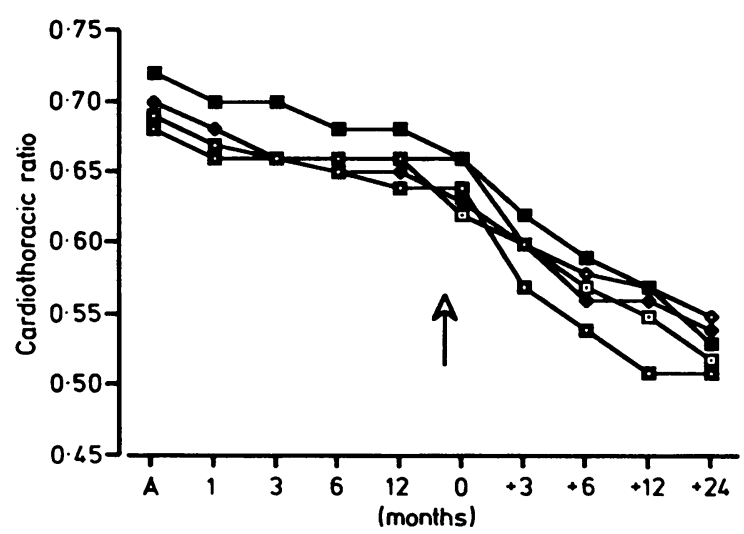

Fig 1 Heart size (cardiothoracic ratio) in the five survivors of late operation (group 1). A, admission to hospital; $O$, operation (arrow).

mode echocardiography showed a left ventricular shortening fraction of $30 \%, 32 \%$, and $35 \%$.

Seven $(58 \%)$ ) of the 12 patients in group 1 died. Aortography in two of the five survivors showed a patent left coronary artery. In the remaining threethe left coronary artery was seen on cross sectiona $\mathrm{B}$. echocardiography. None of the survivors has signs of aortic insufficiency or supravalvar aortic or pulmonary stenosis.

\section{GROUP 2}

Two $(22 \%)$ out of the nine infants died at or shortly after operation. One was the baby admitted in 1977 who had a extensive operation for a massive infarc $N$ tion with mitral insufficiency. The second underwent isolated reimplantation of the anomalous lefto coronary artery and died three weeks after operation from a severe pulmonary infection. At that time he had partly recovered, with a significant decrease of? the cardiomegaly (cardiothoracic ratio $0.67 v 0.72$ ) and a moderate increase in the left ventricularo shortening fraction $(16 \% v 9 \%)$.

The remaining seven patients survived operation and have been followed up for 7-45 months (meang 


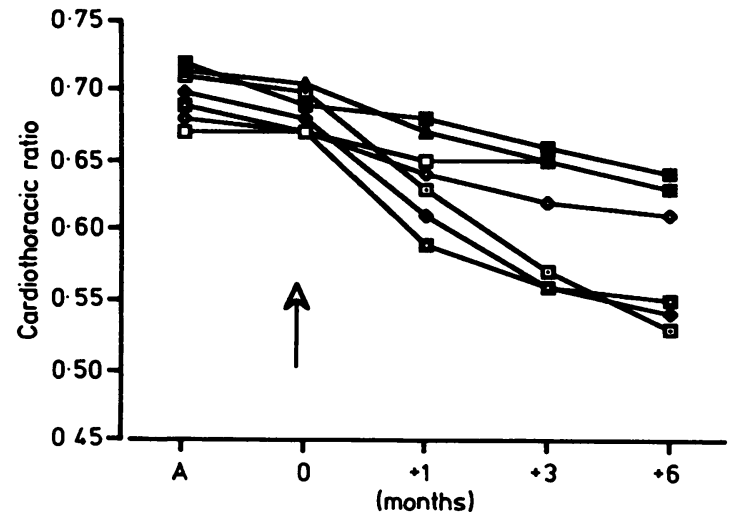

Fig 2 Heart size (cardiothoracic ratio) in the seven survivors of earlier operation (group 2). A, admission to hospital; $O$, operation (arrow).

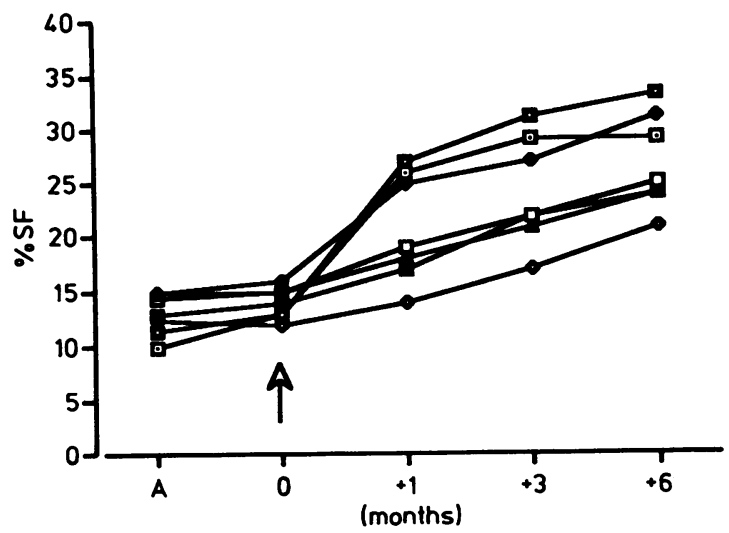

Fig 3 Left ventricular shortening fraction in the seven survivors of earlier operation (group 2). A, admission to hospital; $O$, operation (arrow); $\% S F$, shortening fraction of the left ventricular diameter on $M$ mode echocardiography.

(SD) 20 (11) months). They are all well. In three patients there was a considerable improvement. Within one month heart failure disappeared, cardiomegaly decreased with a reduction in mean (SD) cardiothoracic ratio from $0.68(0.01)$ to $0.57(0.02)$ (fig 2), and the mean (SD) left ventricular shortening fraction increased from $13(12 \%)$ to $27(5) \%$ (fig 3 ). The electrocardiogram showed some improvement in the infarction pattern in two patients and complete recovery in one in whom $R$ waves reappeared in leads $I$ and aVL. In the remaining four patients the improvement was slower but constant and these children were discharged with controlled congestive heart failure. In two cardiomegaly decreased and left ventricular function was almost normal after 13 and 17 months. Follow up is short (seven and ten months) in the remaining two patients but they are improving progressively with less cardiomegaly (a fall in the cardiothoracic ratio from 0.69 to 0.63 ) and an improved shortening fraction (from $14 \%$ to $23 \%$ ).

The overall mortality for group 2 was two $(22 \%)$ out of nine. The left coronary artery was seen on cross sectional echocardiography in all five patients followed up in our department. They did not have valvar aortic stenosis or supravalvar pulmonary stenosis or any valvar insufficiency.

\section{Discussion}

At admission cardiovascular disease was equally severe in both treatment groups. We know that a statistical comparison between two consecutive groups can be criticised because the earlier patients (group 1) will not have benefited from recent medical improvements and will have had longer for late complications to appear. Nevertheless, the main improvement in medical treatment is the use of vasodilators to treat cardiac failure. This is unlikely to have improved the outcome of medically treated patients, especially as three of the five deaths occurred in patients with controlled heart failure. It is also unlikely that the shorter follow up of group 2 significantly affected the overall outcome because most severe complications, mainly sudden death, occur in the first year after infarction and not when the two coronary arteries are patent. In all but two patients in group 2 follow up exceeded one year; all had a patent left coronary artery on cross sectional echocardiography and Doppler study, and left ventricular function continued to improve in all survivors in group 2.

The difference in outcome between the two groups is so striking that early operation must have advantages. Not only was the overall mortality considerably less in group 2 than in group 1, but surgical mortality in group 2 was less than natural mortality in group 1. Also, surgical mortality was not higher in infants than in older children; this result must have been influenced by improvements in cardiac surgery in the past decade, however. The striking difference between our series and earlier one ${ }^{13-5}$ is the low mortality that we found in the younger infants. This must be the result of improvements in neonatal cardiac surgery. Advances in neonatal bypass techniques, myocardial preservation, and handling of tiny coronary arteries (for anatomical correction of simple transposition of the great arteries) may have had cumulative, beneficial effects. We also believe that the systematic use of left ventricular assistance at the end of the operation was helpful, that it is important to limit the procedure to the coronary relocation in these young patients, and to avoid any 
other operation on the left ventricle or the mitral valve.

This study showed that even in medically treated patients who did well, left ventricular function improved only when perfusion by a double coronary artery system was restored-despite the claim that the supposed territory of the anomalous left coronary artery was said to be fibrotic. Early operation was associated in three of the seven survivors with a striking (and somewhat unexpected) improvement in the areas that were supposed to be definitively damaged by the infarction. The younger the patient the quicker the recovery of the left ventricular dysfunction. This probably reflects the enormous potential for tissue growth in infants. Now that early operation has become safer we think that this potential in infants is another argument for operating early. But how early? Should we continue to wait a few weeks or should we operate as soon as possible, perhaps even in the acute phase of the infarction, to enhance the possibility of a quick and complete recovery? Further comparative studies are needed to answer this question.

\section{References}

1 Driscoll DJ, Nihill MR, Mullins CE, Cooley DA, McNamara DG. Management of symptomatic infants with anomalous origin of the left coronary artery from the pulmonary artery. Am J Cardiol 1981;47:642-8.
2 Wesselhoeft H, Fawcett JS, Johnson AL. Anomalous C origin of the left coronary artery from the pulmonary trunk. Its clinical spectrum, pathology and pathophysiology, based on a review of 140 cases with seven further cases. Circulation 1968;38:403-25.

3 Arciniegas E, Farooki ZQ, Hakimi M, Green EW. Management of anomalous left coronary artery from the pulmonary artery. Circulation 1980;62 (suppl I): 180-9.

4 Laborde F, Marchand M, Leca F, Jarreau MM, Dequirot A, Hazan E. Surgical treatment of anomalous origin of the left coronary artery in infancy and childhood. J Thorac Cardiovasc Surg 1981;82: 423-8.

5 Grace RR, Angelini P, Cooley DA. Aortic implantation of anomalous left coronary artery arising from pulmonary artery. Am J Cardiol 1977;39:608-13.

6 Bunton R, Jonas RA, Lang P, Azaria J, Rein JT, Castaneda AR. Anomalous origin of left coronary artery from pulmonary artery. Ligation versus establishment of a two coronary artery system. $J$ Thorac Cardiovasc Surg 1987;93:103-8.

7 Vouhé PR, Baillot Vernant F, Trinquet F, et al. Anomalous left coronary artery from the pulmonary artery in infants: which operation? When? $J$ Thorac Cardiovasc Surg 1987;94:192-9.

8 Levitsk S, Van Der Horst RL, Hastreiter AR, Fisher EA. Anomalous left coronary in the infant. Recovery of ventricular function following early direct aortic reimplantation. J Thorac Cardiovasc Surg 1980; 79:598-602.

9 Piéchaud JF, Shalaby L, Kachaner J, Villain E, Sidi D. Pulmonary artery "stopflow" angiography to visualize the anomalous origin of the left coronary artery from the pulmonary artery in infants. Pediatr Cardiol 1987;8:11-5. 